\title{
Interactive comment on "Quantifying the impacts of human water use and climate variations on recent drying of Lake Urmia basin: the value of different sets of spaceborne and in-situ data for calibrating a hydrological model" by Seyed-Mohammad Hosseini-Moghari et al.
}

Seyed-Mohammad Hosseini-Moghari et al.

hosseini_sm@ut.ac.ir

Received and published: 17 December 2018

Referee \#2: It can be considered as an interesting update in vast literature of Lake Urmia studies while authors tried to use a vast variety of data between 2003 to 2013 to evaluate the situation of Lake Urmia. I think a Major revision are needed prior to evaluating its technical quality. My comments are listed as bellow. 
ments that helped us improving the manuscript. We will try to do our best to consider all your recommendations in the revised version. Below, we have provided a point-bypoint response to your comments.

General comments:

Referee \#2: A technical proof reading is needed since some of the sentences are not understandable.

comment

Response: We will revise the whole manuscript and the manuscript will be checked by a native speaker.

Referee \#2: Your given figures and tables do not necessarily indicate to the discussion you have made.

Response: We provided discussion on all figures and tables. We agree that some part of the discussion might not directly related to the figures and tables which is the lesson we learned from this study. However, we will re-write the result and discussion section with considering your comment.

Referee \#2: Relative error in your models is important since figures are dimensionless. Still, given figures seems to have unacceptable errors.

Response: We can calculate relative error. But we think you were misled because all figures have dimension. We assume that you did not follow the different calibration variants. If you see some unacceptable errors in the figures, these errors are related to the variables which did not consider as an objective function in the calibration process (see different calibration variants).

Referee \#2: Methodology should be revised since it is not clear how you evaluated the figures in discussion.

Response: We do not understand the comment well. However, we will revise the methodology section.

Printer-friendly version

Discussion paper 
Specific comments:

Referee \#2: You are suggesting that the Lake would have been vanished any way but there are a vast literature against your statement. What is your comments? You should also add sentences in the text about it.

Response: We do not suggest at all that the lake would have vanished without human water use. On page 21 line 28, for example, we state the following:

"Still, even in the WGHM-NAT, the average inflow into the lake from 2009-2013 of $3,670 \times 106 \mathrm{~m} 3$ would have been only enough to keep the lake from further loosing volume but would not have been enough for a recovery to conditions between 2003 and 2007 (Fig. 9b),"

Referee \#2: One of the main factors in your study is the calibration of satellite data and application of filters on data which are main issues. E.g. In GRACE data how did you manage to use 2degree precision into such a cristal clear results?

Response: We agree with you. We used satellite data for three objectives including the irrigated area, lake level (and extent) and TWSA. Irrigated area and lake level were taken from previous studies which they needed filters on data before application. Hence, among all used satellite data, here we only discuss GRACE data. To deal with your mentioned issue about GRACE data, we have used CSR mascon solutions product which based on Save et al. (2016) do not need any filters. Also, as we mentioned in the manuscript, we know that it is recommended GRACE data products only for areas with at least 100,000 km2 (Watkins et al., 2015; Landerer and Swenson, 2012). But studies by Tourian et al. (2015) and Lorenz et al. (2014) showed that signal strength or the so-called gravimetric resolution is determining the applicability of GRACE data. In fact, Lake Urmia basin has experienced an $8 \times 109 \mathrm{~m} 3$ change in the water volume in the last decade, which allows the use of GRACE for monitoring the changes in water storage in the basin (Tourian et al., 2015). This fact is supported by the very small gain factor of 1.0083 for the Lake Urmia basin based on Community

Printer-friendly version

Discussion paper 
Land Model 4 (CLM4) for spherical harmonic solutions (Landerer and Swenson, 2012), which is the factor with which signal attenuation due to leakage could be balanced. We can assume errors of the applied GRACE monthly time series of TWSA are small compared to the uncertainty of TWSA as computed by WGHM, such that model calibration against GRACE TWSA is meaningful.

Referee \#2: Why did you use a time length between 2003 to 2013 ? Since the decreasing trend have already started from late 90's.

Response: The main reason was shortage of data. The GRACE data and irrigated area which play important roles in this study were not available for late 90's. As a results we faced substantial missing data before 2000 .

Referee \#2: There are a lot of missing data in historical time series records of the region. How did you manage to remove them? are they satisfactorily acceptable methods to be applied?

Response: We disagree. There are no significant missing data for 2003-2013. The method used for filling the gaps are as follows:

-Irrigated area: There is no missing data in this data (except 2013).

-GRACE data: There are some missing data (8 months) in its observations which have filled using linear interpolation.

-Inflow into the Lake: There is no missing data in the dataset of annual inflow into the lake.

-Groundwater levels: We assessed data of 635 wells then we removed the wells with more than 12 months or six consecutive months missing values. After removing the wells with significant missing values, we have worked on 284 wells. If there are missing data in the dataset of these 284 wells, we used linear interpolation (if only one month is missing) or linear regression (with the nearest well in common period) for filling the gaps in data.

Printer-friendly version

Discussion paper 
-Water withdrawals: There is no missing data in this data.

-Precipitation: Almost there is no missing data in the studied stations between 20032013. Few missing data filled in comparison with near stations.

-Temperature: There is no missing data in this data.

-Lake volume: There are some missing data for lake volume which have filled using linear interpolation.

Referee \#2: Page 9, Line 20, Calibration: You have to give the error evaluation if you have used "try and error" method.

Response: We used trial and error to determine the most appropriate parameters of model in each calibration of variant based on the evaluating the model error with respect to the observations used, while trying to keep the number of adapted parameters at a minimum. We provide the final errors in Table 4. We do not think that it is interesting for the reader to provide the errors/model performances for all trials (there were many).

Referee \#2: Page 12, Performance criteria, Line 5: These criteria do not show relative error in your models since RMSE number is not necessarily satisfactory.

Response: We will calculate relative error in the revised version.

Referee \#2: Page 13, Figure 7: None of these figures indicate to an acceptable calibration.

Response: This figure does not show any calibration results. This figure shows the inputs of model in different variants, not the model's output. Thus, there is no reason to fit the lines in this figure.

Referee \#2: Page 14, Figure 8d: The discrepancy and error is growing in your anomalies. How do you interpret? 
Response: It should be noted that Figure 8d shows change not anomalies. Anyway, we agree that the error in the second half of the time series is bigger than the first half. However, the difference in errors is minor. Also, discrepancies in groundwater storage (e.g. in peak of seasonality) can represent some minor discrepancy in groundwater storage changes. If you consider Figure 8c, which shows the normalized groundwater storage, there is no growing in discrepancy.

Referee \#2: Page 18-23: Your discussions are too long, yet none of them are visuable from given tables and figures. It is a very long article, yet given informations are narriative and reader should accept your sentences without having a chance to approve it.

Response: We will re-write the results and discussions considering your comment.

Thank you very much again for your time and for providing valuable comments.

\section{References}

Bavil, S. S., Zeinalzadeh, K., and Hessari, B.: The changes in the frequency of daily precipitation in Urmia Lake basin, Iran, Theoretical and Applied Climatology, 133(1-2), 205-214, doi:10.1007/s00704-017-2177-7, 2018.

Farokhnia, A.: Impact of Land Use Change and Climate Variability on Urmia Basin Hydrology (Dissertation) Tarbiat Modares University, Agricultral department (in Persian), 2015.

Landerer, F. W., and Swenson, S. C.: Accuracy of scaled GRACE terrestrial water storage estimates, Water resources research, 48, doi:10.1029/2011WR011453, 2012.

Lorenz, C., Kunstmann, H., Devaraju, B., Tourian, M. J., Sneeuw, N., and Riegger, Discussion paper

J.: Large-scale runoff from landmasses: a global assessment of the closure of the 
hydrological and atmospheric water balances, Journal of Hydrometeorology, 15, 2111 2139, doi:10.1175/JHM-D-13-0157.1, 2014.

Save, H., Bettadpur, S., and Tapley, B. D.: HighâĂŘresolution CSR GRACE RL05 mascons, Journal of Geophysical Research: Solid Earth, 121, 7547-7569, doi:10.1002/2016JB013007, 2016.

Tourian, M. J., Elmi, O., Chen, Q., Devaraju, B., Roohi, S., and Sneeuw, N.: A spaceborne multisensor approach to monitor the desiccation of Lake Urmia in Iran, Remote Sensing of Environment, 156, 349-360, doi:10.1016/j.rse.2014.10.006, 2015.

Watkins, M. M., Wiese, D. N., Yuan, D. N., Boening, C., and Landerer, F. W.: Improved methods for observing Earth's time variable mass distribution with GRACE using spherical cap mascons, Journal of Geophysical Research: Solid Earth, 120, 2648-2671, doi:10.1002/2014JB011547, 2015.

Interactive comment on Hydrol. Earth Syst. Sci. Discuss., https://doi.org/10.5194/hess-2018318, 2018. 